Author's Accepted Manuscript (AAM)

Moneta, G. B. (2017). Validation of the Short Flow in Work Scale (SFWS). Personality and Individual

Differences, 109, 83-88. DOI: 10.1016/j.paid.2016.12.033

Submitted: September 17, 2016

Revised: December 14, 2016

Accepted: December 19, 2016

Published online: January 4, 2017

Published (expected): April 15, 2017

\title{
Validation of the Short Flow in Work Scale (SFWS)
}

\author{
Giovanni B. Moneta \\ London Metropolitan University, London, UK
}

Submitted: September 17, 2016

Resubmitted: December 14, 2016

Accepted: December 19, 2016

Word count: 5000

Author at: School of Social Sciences - Psychology, London Metropolitan University, Tower

Building, 166-220 Holloway Road, London N7 8DB, United Kingdom.

Email address: g.moneta@londonmet.ac.uk 


\begin{abstract}
This paper describes the validation of a short scale measuring flow in work. Study 1 used exploratory factor analysis on data gathered from 582 workers, and indicated unidimensionality. Study 2 used confirmatory factor analysis on two-wave data gathered from 101 workers, and corroborated the factor structure, ruled out response styles, and established scalar invariance across administrations. In Study 3, a sample of 492 workers completed the scale, other two flow scales, and scales measuring work engagement and positive affect. Confirmatory factor analysis revealed that the scale converges satisfactorily with other flow scales and has more discriminant validity. Study 4 used multilevel confirmatory factor analysis on repeated workday surveys gathered from 118 workers, and corroborated the factorial validity and factorial invariance of the scale. The findings indicate that the scale produces valid and reliable scores when used to measure flow both as a domainspecific disposition and as a workday state.
\end{abstract}

Keywords: Flow, Flow Scales, Factorial Validity, Factorial Invariance, Multilevel Confirmatory Factor Analysis. 


\section{Introduction}

Flow is a state of profound task-absorption and intense concentration that makes a person feel one with the activity (Csikszentmihalyi, 1975/2000). Flow was later conceptualized as a state, a broad disposition, and a domain-specific disposition (e.g., Jackson, Martin, \& Eklund, 2008). In the past two decades, researchers in the field of work psychology have increasingly focused on the occurrence of flow in the work context across a wide range of occupations and organizational contexts, including scientists (Quinn, 2005), software engineers (Debus et al., 2014), and teachers (Salanova, Bakker, \& Llorens, 2006). They identified antecedents of flow at work, including individual difference components (e.g., Eisenberger et al., 2005) and work environment factors (e.g., Mäkikangas et al., 2010), and consequences of flow at work, including enhanced employee's psychological well-being (e.g., Debus et al., 2014) and enhanced job performance (e.g., Eisenberger et al., 2005).

In response to the growing interest in flow research in the organizational context, this paper presents four studies aimed at validating the shortest flow scale developed to date, the Short Flow in Work Scale (SFWS; Moneta, 2012b). The goal is to provide researchers with a scale that is consistent with the original definition flow, has comparatively good psychometric properties, and is so short that can be included in longitudinal, especially diary studies that include other scales and require a compact survey format. Studies 1 through 3 evaluate the scale when it is used to measure flow as a domain-specific disposition, whereas Study 4 evaluates the scale when it is used to measure flow as a workday state.

\section{Study 1: Scale Development}

Csiksentmihalyi (1975/2000) identified flow by asking surgeons, composers, dancers, and athletes to report their most challenging experiences. The most insightful descriptions of flow were then selected to create the first measurement method for flow, the Flow Questionnaire (FQ; Csikszentmihalyi \& Csikszentmihalyi, 1988). The FQ presents three 
quotations that together capture the three key components of flow in Csikszentmihalyi's (1975/2000) original conceptualization: (a) centering of attention, (b) loss of selfconsciousness, and (c) merging of action and awareness. The FQ then asks respondents whether they ever felt experiences similar to those described in the quotations, providing a single yes/no answer. The FQ appears to be a valid way of measuring the prevalence flow in general and in specific contexts such as work or leisure (Moneta, 2012a, 2012b).

The SFWS was derived from the quotations of the FQ with the aim of providing a measure of the intensity of flow - as opposed to its mere occurrence or non-occurrence - that is experienced in work situations. A series of small-scale validation studies using a pool of nine items suggested that the flow components a-c could be measured by three items each. However, inter-item correlations were too high and the interviewed participants noticed strong similarities between the items measuring the same component of flow. These observations, together with the overarching goal of producing a short scale, led to selecting the three items shown in the Appendix, which are designed to measure the flow components $\mathrm{a}-\mathrm{c}$, in that order. The instructions for participants and response scale were taken from the Work Preference Inventory (WPI; Amabile et al. 1994). The goal of this study was to explore the factor structure of the scale.

\section{Method}

\section{Participants and Procedure}

A convenience sample of 582 workers from various occupations was recruited. The age range was $18-74$ years $(M=34.82, S D=10.53)$; $282(48.5 \%)$ were males, $300(51.5 \%)$ were females; 511 (87.8\%) earned an undergraduate degree, 427 (73.4\%) earned a postgraduate degree. Participants completed the SFWS as an online survey. 


\section{Statistical Analysis}

The dimensionality of the SFWS was explored using principal axis factor analysis. The number of factors to be extracted was determined by parallel analysis using ViSta Version 7.9.2.6 (Valero-Mora \& Friendly, 2014).

\section{Results and Discussion}

Table 1 shows the descriptive statistics of the item and scale scores. Cronbach's alpha was satisfactory. The intercorrelations of the item scores were fair. Parallel analysis indicated the presence of only one factor. The factor accounted for $56.45 \%$ of the variance. The factor loadings ( 0.75 for item $1,0.78$ for item 2 , and 0.72 for item 3$)$ were strong and balanced. In all, the SFWS appears to have satisfactory internal consistency and good construct validity as a unidimensional scale.

\section{Study 2: Assessment of Construct Validity and Factorial Invariance}

The goal of the present study was to evaluate the construct validity of the SFWS on a new sample. The analysis used data gathered through a two-wave design. The design allowed assessing factorial validity including response styles, that is, the tendency for a scale to elicit consistent idiosyncratic interpretations of its items (Pitts, West, \& Tein, 1996). Moreover, it allowed assessing the factorial invariance of the scale (Hoyle \& Smith, 1994), that is, the extent to which the construct of flow is measured similarly between occasions in respect to the relationships between flow and the items (intercepts of the items and factor loadings) and precision (item measurement errors).

\section{Method}

Participants and Procedure

A convenience sample of 172 workers from various occupations was recruited to participate in a two-wave study, with waves three months apart. Of these, $101(58,7 \%)$ completed both waves and their data could be matched; these participants did not differ in 
gender, age, and initial SFWS scores from the others as assessed by chi-square and t-tests.

Their age range was $21-69$ years $(M=39.2, S D=11.0)$; $43(42.6 \%)$ were males, $58(57.4 \%)$

were females; $92(91.1 \%)$ earned an undergraduate degree, 68 (57.4\%) earned a postgraduate degree. Participants completed the SFWS as two online surveys.

\section{Statistical Analysis}

The construct validity and factorial invariance of the SFWS were evaluated by confirmatory factor analysis (CFA) using LISREL 8.8 (Jöreskog \& Sörbom, 1996) and maximum likelihood (ML) estimation. Flow at time 1 and flow at time 2 were defined as two latent variables, and the respective items as congeneric indicators of the latent variables.

The chi-square test (Jöreskog \& Sörbom, 1996) was used to assess the strict goodness of fit of the models. The models were then assessed for close fit using Hu and Bentler's (1999) criteria with the cut-off point of 0.05 for the Root Mean Square Error of Approximation (RMSEA), and of .95 for the Comparative Fit Index (CFI) and the NonNormed Fit Index (NNFI).

\section{Results and Discussion}

Table 2 shows the descriptive statistics of the items and scale across the two waves. Cronbach's alpha was satisfactory on both occasions. The correlation of the scale scores between occasions was fair. The mean item and scale scores were similar in the two occasions.

Table 3 shows the goodness of fit indexes of the estimated models. Model 1 imposed no restrictions on the intercepts of the items, factor loadings, and item measurement errors. The chi-square test was nonsignificant, indicating that the model fits, and all other goodness of fit statistics revealed excellent fit, indicating that the latent variable of flow is similar in the two administrations (configural invariance). 
Model 2 was identical to Model 1 except for it allowed the item measurement errors to correlate across the time 1 and time 2 administrations (e.g., the error of item 1 measuring flow at time 1 was allowed to covary with the error of item 1 measuring flow at time 2 ). The model showed excellent fit, and the comparison in fit between this and Model 1 was nonsignificant (difference chi-square $=2.5, \mathrm{df}=3, p=0.475$ ), indicating that the scale does not elicit response styles.

Model 3 was identical to Model 1 except for it constrained the factor loadings to be identical at times 1 and 2 (e.g., the loading of item 1 measuring flow at time 1 was forced to be identical to the loading of item 1 measuring flow at time 2). The model showed good fit, and the comparison in fit between this and Model 1 was nonsignificant (difference chisquare $=6.24, \mathrm{df}=3, p=0.100$ ), indicating that respondents attribute the same meaning to the latent construct of flow across administrations (metric invariance).

Model 4 was identical to Model 3 except for it constrained the intercepts of the items to be identical at times 1 and 2 (e.g., the intercept of item 1 measuring flow at time 1 was forced to be identical to the intercept of item 1 measuring flow at time 2). The model showed good fit, and the comparison in fit between this and Model 3 was nonsignificant (difference chi-square $=3.16, \mathrm{df}=3, p=0.368$ ), indicating that the levels of the items are equal across administrations (scalar invariance).

Model 5 was identical to Model 4 except for it constrained the item measurement errors to be identical at times 1 and 2 (e.g., the error of item 1 measuring flow at time 1 was forced to be identical to the error of item 1 measuring flow at time 2). The model showed poor fit, and the comparison in fit between this and Model 4 was significant (difference chisquare $=12.07, \mathrm{df}=3, p=0.007)$, indicating that the latent construct of flow is not measured identically across administrations (strict invariance). 
Therefore, the scalar invariance Model 4 was retained as the final model. Figure 1 shows the factor loadings, item measurement errors, and correlation between factors. The factor loadings are strong and the scale is free from response styles, supporting the factorial validity of the SFWS.

Scalar invariance implies that the flow scores can be compared across administrations, but flow is measured with different precision between the administrations. In particular, the model-based estimate of scale reliability (e.g., Raykov, 1997) was satisfactory (0.77) at time 1 and good (0.87) at time 2. With this caveat, the factorial invariance of the SFWS is supported.

\section{Study 3: Assessment of Convergent and Discriminant Validity}

Jackson and Csikszentmihalyi (1999) have proposed that flow includes six components in addition to the three components captured by the SFWS: sense of control over one's actions, autotelic experience, loss of time-awareness or time acceleration, clear proximal goals, unambiguous feedback, and dynamic balance between challenge and skill. Therefore, the first goal of this study was to assess the convergent validity of the SFWS in respect to scales that are designed to capture additional components of flow.

Some researchers have argued that only some of the nine components are indicators of flow (i.e., experiences that can be caused by flow), whereas the remaining are either antecedents of flow or effects of flow (see review by Hoffman and Novak, 2009). The likely consequence of including antecedents and effects of flow in a flow scale is that the resulting overall measure of flow will have poorer discriminant validity. Therefore, the second goal of this study was to assess the discriminant validity of the SFWS relative to flow scales that capture more components of flow.

Discriminant validity was assessed using two constructs that have emerged as potentially overlapping with the construct of flow in the field of work psychology: work 
engagement and positive affect. Schaufeli and co-workers (2002) have defined work engagement as characterized by vigor, dedication, and absorption in one's work. Affect is a general term representing positive or negative moods and emotions, mapping them onto a positive-negative valence dimension and differentiating them according to their level of activation (Russell \& Carroll, 1999). Positive affect includes emotions such as joy, interest, and alertness.

Method

Participants and Procedure

A convenience sample of 492 workers from various occupations was recruited. The age range was $18-80$ years $(M=37.52, S D=11.94) ; 204(41.5 \%)$ were males, $288(58.5 \%)$ were females; 395 (80.3\%) earned an undergraduate degree, 214 (43.5\%) earned a postgraduate degree. Participants completed the following scales as an online survey. Measures

Short Flow in Work Scale (SFWS). This is the questionnaire developed in Study 1. Flow Short Scale (FSS). The 10-item FSS (Engeser \& Rheinberg, 2008) measures all the components of flow described in the introduction to Study 3 (e.g., "I am totally absorbed in what I am doing”), except for autotelic experience, on a scale ranging from 1 (Not at all) to 7 (Very much). The preamble was: “These questions relate to feelings you may experience during your work.” Cronbach's alpha was 0.92 (Engeser \& Rheinberg, 2008).

The Short Dispositional Flow Scale-2 (SDFS-2). The 9-item SDFS-2 (Jackson, Martin \& Eklund, 2008) measures all nine components of flow described in the introduction to Study 3 (e.g., "I am completely focused on the task at hand") on a scale ranging from 1 (Never) to 5 (Always). The preamble was: "These questions relate to the thoughts and feelings you may experience during your work.” Cronbach's alpha was 0.81 (Jackson et al., 2008). 
Utrecht Work Engagement Scale (UWES-9). The 9-item UWES-9 measures the three components of work engagement described in the introduction to Study 3 (e.g., "At my work, I feel bursting with energy") on a scale ranging from 1 (Never) to 7 (Always). Cronbach's alpha ranged between 0.85 and 0.92 across national samples (Schaufeli et al., 2002).

The Positive and Negative Affect Scale Short Form (I-PANAS-SF).

The I-PANAS-SF is a list of ten adjectives, five measuring positive affect (e.g., "Attentive") and five measuring negative affect (e.g., "Nervous"). The preamble was: "Please read the following adjectives in detail and think if you have those feelings when you work." Adjectives were scored on a five-point scale ranging from 1 (None) to 5 (Very much). Cronbach's alpha was 0.80 for positive affect (Thompson, 2007).

Statistical Analysis

The disattenuated correlations among the study variables were estimated by confirmatory factor analysis (CFA) using LISREL 8.8 (Jöreskog \& Sörbom, 1996) and maximum likelihood (ML) estimation. The variables were defined as latent variables, and the respective items as congeneric indicators of the latent variables.

\section{Results and Discussion}

Table 4 shows the descriptive statistics and intercorrelations of the study variables. All variables had satisfactory to good internal consistency, and were positively intercorrelated as expected.

The model did not fit strictly (chi-square $=2934.31, \mathrm{df}=584, p<0.001)$ and did not fit closely $(\mathrm{RMSEA}=0.091, p[\mathrm{RMSEA}<0.05]<0.001)$, but the remaining indexes suggested satisfactory fit $(\mathrm{CFI}=0.95 ; \mathrm{NNFI}=.95)$. It was possible to achieve close fit by adding a small number of item error correlations within some of the scales. However, the correlations between factors were nearly unaffected by such modification. Therefore, the interpretation will be based on the model without correlated item errors, which is shown in Figure 2. 
The SFWS correlated fairly with both the FSS and the SDFS-2, which correlated strongly with each other. Therefore, the convergent validity of the SFWS is satisfactory but inferior to that of the other flow scales.

The UWES-9 and the I-PANAS positive affect correlated strongly with each other. The SFWS correlated moderately, whereas the FSS and the SDFS-2 strongly, with both the UWES-9 and the I-PANAS positive affect. Therefore, the discriminant validity of the SFWS is satisfactory and superior to that of the other flow scales.

\section{Study 4: Assessment of Construct Validity and Factorial Invariance as State Measure}

There are three key reasons why a valid measure of a disposition may not be a valid measure of states when the scale is administered repeatedly to the same participants. First, participants may try to be consistent in their answers. Second, experiences measured by an item may not change from one measurement occasion to the other. Finally, experiences measured by an item may be more salient on specific measurement occasions, for example if they are linked to specific work tasks. If one or more of these possibilities apply, a scale will not have factorial invariance across repeated measures, and will have construct validity only on the scale scores aggregated within-subjects across the repeated measures.

The goal of this study was to assess the construct validity and factorial invariance of the SFWS when used as a measure of workday states in a daily diary study design. As Breevaart and co-workers (2012) explained extensively for the validation of the Utrecht Work Engagement Scale (UWES; Schaufeli et al., 2002) as a measure of daily states, in this design, the factorial invariance of the SFWS is the extent to which the construct of flow is measured similarly between the two levels of analysis - worker and observation - in respect to the relationships between flow and the items (factor loadings). 


\section{Method}

Participants and Procedure

A convenience sample of 118 workers from various occupations was recruited. The age range was $19-62$ years $(M=30.44, S D=8.47) ; 70(59.3 \%)$ were males, $48(40.7 \%)$ were females; 94 (79.7\%) earned an undergraduate degree, 48 (40.7\%) earned a postgraduate degree.

Participants completed an online workday survey daily from start to completion of a work project. The survey first asked: "Please briefly describe below what you have been doing on the project since the last time you completed a workday project survey and any event that you find important." Then, the SFWS was introduced using the following preamble: "Please answer the following questions thinking of what you did on the project and how you felt in carrying out the project activities you just described." Participants were instructed not to answer a survey if they had not worked on the project since answering the previous survey.

The 118 work projects lasted from 2 to 14 calendar days $(M=4.79, S D=3.39)$. A total of 468 surveys were completed. The mean time lapse between consecutive surveys was 1.46 days $(S D=1.84)$.

\section{Statistical Analysis}

The construct validity and factorial invariance of the SFWS were evaluated by multilevel confirmatory factor analysis (MCFA) using LISREL 8.8 (Jöreskog \& Sörbom, 1996) and maximum likelihood (ML) estimation, in which participants belong to Level 2 and workday measures belong to Level 1. In both the between-subjects (Level 2) model and the within-subjects (Level 1) model, flow was defined as a latent variable, and the respective items as congeneric indicators of the latent variable. 


\section{Results and Discussion}

Table 5 shows the descriptive statistics of the items and scale calculated betweensubjects and within-subjects. Cronbach's alpha was good between-subjects and satisfactory within-subjects. The intercorrelations of the item scores were fair both between-subjects and within-subjects.

The factor loadings were constrained to be identical in the between-subjects and within-subject models (e.g., the factor loading of item 1 measuring flow in the betweensubjects model was forced to be identical to the factor loading of item 1 measuring flow in the within-subjects model). The model fitted strictly (chi-square $=3.24, \mathrm{df}=3, p=0.355$; RMSEA $=0.019, p[\mathrm{RMSEA}<0.05]=0.742, \mathrm{CFI}=0.99, \mathrm{NNFI}=0.98)$, indicating the relationships between the latent variable of flow and the items are the same between levels. The model-based estimate of scale reliability was excellent (0.95) between-subjects and good (0.82) within-subjects.

Figure 3 shows the factor loadings and item measurement errors for Model 1. The factor loadings were strong and in line with those estimated in Studies 1-3, and hence support the factorial validity of the SFWS when used to measure workday states. The factor loadings were the same between levels, indicating that respondents attribute the same meaning to the latent construct of flow across administrations repeated daily, and hence support the factorial invariance of the SFWS when used to measure workday states.

\section{General Discussion}

This paper presented four studies aimed at validating the SFWS (Moneta, 2012b), which is grounded in the original, three-component definition of flow (Csikszentmihalyi, 1975/2000), and measures flow in work as a domain-specific disposition using only three items. Study 1 indicated that the scale is unidimensional. Study 2 corroborated the factor structure, ruled out response styles, and established scalar invariance across two 
administrations, three months apart. Study 3 indicated that the scale has satisfactory convergent validity and more discriminant validity than the other two flow scales - which tap more than the three original components of flow - suggesting that it may be advisable to remain committed to the original definition of flow. Study 4 corroborated the factorial validity and factorial invariance of the scale when used to measure flow as a workday state.

Two key limitations should be considered. First, the study participants were highly educated and from a wide range of occupations, and hence we do not know if factorial validity and factorial invariance would hold for less educated participants and specific occupational groups. Second, the scale uses only one item to measure each original flow component, and hence it should be expanded in order to measure each component separately.

With these caveats, the present study shows that the SFWS has satisfactory construct validity, internal consistency, convergent validity, and discriminant validity, and it can be used to measure flow both as a domain-specific disposition and as a workday state. Being the shortest flow scale available, the SFWS is a method of choice in surveys when length is an issue. Because of its discriminant validity, the SFWS is a method of choice for those organizational researchers who commit to the original definition of flow and/or aim to disentangle the effects of flow from the effects of other variables, such as work engagement and positive affect, that are conceptually related to, but distinct from flow. 


\section{References}

Amabile, T. M., Hill, K. G., Hennessey, B. A., \& Tighe, E. (1994). The work preference inventory: Assessing intrinsic and extrinsic motivational orientations. Journal of Personality and Social Psychology, 66, 950-967.

Breevaart, K., Bakker, A.B., Demerouti, E., \& Hetland, J. (2012). The measurement of state work engagement: A multilevel factor analytic study. European Journal of Psychological Assessment, 28, 305-312

Csikszentmihalyi, M. (1975/2000). Beyond boredom and anxiety: Experiencing flow in work and play (2nd edition). San Francisco: Jossey Bass.

Csikszentmihalyi, M., \& Csikszentmihalyi, I. (1988). Optimal experience: Psychological studies of flow in consciousness. Cambridge: Cambridge University Press.

Debus, M. E., Sonnentag, S., Deutsch, W. \& Nussbeck, F. W. (2014). Making flow happen: The effects of being recovered on work-related flow between and within days. Journal of Applied Psychology, 99, 713-722.

Engeser, S., \& Rheinberg, F. (2008). Flow, moderators of challenge-skill-balance and performance. Motivation and Emotion, 32, 158-172.

Eisenberger, R., Jones, J. R., Stinglhamber, F., Shanock, L., \& Randall, A. T. (2005). Flow experiences at work: for high need achievers alone? Journal of Organizational Behavior, 26, 755-775.

Jackson, S. A., \& Csikszentmihalyi, M. (1999). Flow in sports: The keys to optimal experiences and performances. Champaign, IL: Human Kinetics.

Jackson, S. A., Martin, A. J., \& Eklund, R. C. (2008). Long and short measures of flow: The construct validity of the FSS-2, DFS-2, and new brief counterparts. Journal of Sport \& Exercise Psychology, 30(5), 561. 
Hoffman, D. L. \& Novak, T. P. (2009). Flow online: Lessons learned and future prospects. Journal of Interactive Marketing, 23, 23-34.

Hoyle, R. H., \& Smith, G. T. (1994). Formulating clinical research hypotheses as structural equation models: A conceptual overview. Journal of Consulting and Clinical Psychology, 62, 429-440.

Hu, L., \& Bentler, P. M. (1999). Cutoff criteria for fit indices in covariance structure analysis: Conventional versus new alternatives. Structural Equation Modeling, 6, 1-55.

Jöreskog, K. G., \& Sörbom, D. (1996). LISREL 8: User's reference guide. Chicago, IL: Scientific Software International, Inc.

Mäkikangas, A., Bakker, A. B., Aunola, K., \& Demerouti, E. (2010). Job resources and flow at work: Modelling the relationship via latent growth curve and mixture model methodology. Journal of Occupational and Organizational Psychology, 83, 795-814.

Moneta, G. B. (2012a). On the measurement and conceptualization of flow. In S. Engeser (Ed.), Advances in flow research (pp. 23-50). New York, NY: Springer.

Moneta, G. B. (2012b). Opportunity for creativity in the job as a moderator of the relation between trait intrinsic motivation and flow in work. Motivation and Emotion, 36(4), 491-503.

Pitts, S. C., West, S. G., \& Tein, J.-Y. (1996). Longitudinal measurement models in evaluation research: Examining stability and change. Evaluation and Program Planning, 19(4), 333-350.

Quinn, R. W. (2005). Flow in knowledge work: High performance experience in .the design of national security technology. Administrative Science Quarterly, 50, 610-641.

Raykov, T. (1997). Estimation of composite reliability for congeneric measures. Applied Psychological Measurement, 22, 173-184. 
Russell, J. A., \& Carroll, J. M. (1999). On the bipolarity of positive and negative affect. Psychological Bulletin, 125, 3-30.

Schaufeli, W. B., Salanova, M., González-Romá, V., \& Bakker, A. (2002). The Measurement of burnout and engagement: A confirmatory factor analytic approach. Journal of Happiness Studies, 3, 71-92.

Thompson, E. R. (2007). Development and validation of an internationally reliable shortform of the Positive and Negative Affect Schedule (PANAS). Journal of CrossCultural Psychology, 38, 227 -242.

Valero-Mora, P. M., \& Friendly, M. (2014). ViSta 7.9.6.2 (2014, March) [Computer software]. Retrieved from http://www.uv.es/visualstats/Book/ 
Table 1

Study 1: Means and standard deviations of the SFWS items and scale, Cronbach's alpha coefficient (in parentheses), and intercorrelations of the study variables.

\begin{tabular}{|c|c|c|c|c|c|c|}
\hline Variables & $M$ & $S D$ & 1. & 2. & 3. & 4. \\
\hline 1. Item 1 & 2.53 & 0.98 & - & & & \\
\hline 2. Item 2 & 2.52 & 0.90 & $0.59 *$ & - & & \\
\hline 3. Item 3 & 2.18 & 0.88 & $0.54^{*}$ & $0.56^{*}$ & - & \\
\hline 4. Scale & 2.41 & 0.78 & $0.85^{*}$ & $0.85 *$ & $0.82 *$ & $(0.79)$ \\
\hline
\end{tabular}

Note. $n=582$. Range of response scale: $1-4$. “-" means that the corresponding statistic cannot be estimated. $* p<.01$. 


\section{Table 2}

Study 2: Means and standard deviations of the SFWS items and scale, Cronbach's alpha coefficients (in parentheses), and intercorrelations of the study variables measured at times 1 and 2.

\begin{tabular}{|c|c|c|c|c|c|c|c|c|c|c|}
\hline Variables & $M$ & $S D$ & 1. & 2. & 3. & 4. & 5. & 6. & 7. & 8. \\
\hline 1. Time 1 Item 1 & 2.87 & 0.85 & - & & & & & & & \\
\hline 2. Time 1 Item 2 & 2.86 & 0.74 & $0.42 *$ & - & & & & & & \\
\hline 3. Time 1 Item 3 & 2.49 & 0.84 & $0.56^{*}$ & $0.54 *$ & - & & & & & \\
\hline 4. Time 1 Scale & 2.74 & 0.66 & $0.82 *$ & $0.78 *$ & $0.86^{*}$ & $(0.76)$ & & & & \\
\hline 5. Time 2 Item 1 & 2.80 & 0.78 & $0.28 *$ & $0.27 *$ & $0.44 *$ & $0.41 *$ & - & & & \\
\hline 6. Time 2 Item 2 & 2.97 & 0.62 & $0.28 *$ & $0.34 *$ & $0.37 *$ & $0.40^{*}$ & 0.54 & - & & \\
\hline 7. Time 2 Item 3 & 2.41 & 0.80 & $0.42 *$ & $0.35^{*}$ & $0.58 *$ & $0.55^{*}$ & $0.58 *$ & $0.67 *$ & - & \\
\hline 8. Time 2 Scale & 2.73 & 0.63 & $0.38 *$ & $0.37^{*}$ & $0.55^{*}$ & $0.53 *$ & $0.84 *$ & $0.84 *$ & $0.88 *$ & $(0.81)$ \\
\hline
\end{tabular}

Note. $n=101$. Range of response scale: $1-4$. “-” means that the corresponding statistic cannot be estimated. $* p<.01$. 
Table 3

Study 2: Goodness of fit indexes of confirmatory factor analysis (CFA) models for the SFWS.

\begin{tabular}{lcccccc}
\hline Model & Chi- & df & $p$ & CFI & NNFI & RMSEA \\
& Square & & & & & \\
& & & & & & \\
\hline 1. Configural invariance & 7.86 & 8 & 0.448 & 1.00 & 1.00 & 0.000 \\
$\begin{array}{l}\text { 2. Configural invariance } \\
\text { with longitudinally }\end{array}$ & 5.36 & 5 & 0.374 & 1.00 & 0.99 & 0.027 \\
correlated item errors & & & & & & \\
3. Metric invariance & 14.10 & 11 & 0.227 & 0.98 & 0.98 & 0.053 \\
4. Scalar invariance & 17.26 & 14 & 0.243 & 0.98 & 0.98 & 0.048 \\
5. Strict invariance & 29.33 & 17 & 0.032 & 0.93 & 0.94 & 0.085 \\
& & & & & & \\
\hline
\end{tabular}

Note. $n=101 . \mathrm{df}=$ degrees of freedom; RMSEA = Root Mean Square Error of Approximation; CFI $=$ Comparative Fit Index; NNFI $=$ Non-Normed Fit Index. 


\section{Table 4}

Study 3: Means, standard deviations, Cronbach's alpha coefficients (in parentheses), and intercorrelations of the study variables.

\begin{tabular}{llllllll}
\hline Variables & $M$ & $S D$ & 1. & 2. & 3. & 4. & 5.
\end{tabular}

\begin{tabular}{|c|c|c|c|c|c|c|}
\hline 1. Short Flow in Work Scale (SFWS) & 2.64 & 0.81 & $(0.81)$ & & & \\
\hline 2. Flow Short Scale (FSS) & 4.49 & 0.94 & $0.48 *$ & $(0.87)$ & & \\
\hline 3. Short Dispositional Flow Scale-2 & 3.52 & 0.46 & $0.46^{*}$ & $0.61 *$ & $(0.75)$ & \\
\hline (SDFS-2) & & & & & & \\
\hline 4. Utrecht Work Engagement Scale & 5.12 & 1.29 & $0.41 *$ & $0.63 *$ & $0.49 *$ & $(0.95)$ \\
\hline (UWES-9) & & & & & & \\
\hline 5. I-PANAS-SF Positive Affect & 3.57 & 0.69 & $0.35^{*}$ & $0.63 *$ & $0.50 *$ & $0.69 *$ \\
\hline
\end{tabular}

Note. $n=492$. Range of response scale: $1-4$ (SFWS), 1-5 (SDFS-2 and I-PANAS-SF), and 17 (FSS and UWES-9). $* p<.01$. 


\section{Table 5}

Study 4: Means and standard deviations of the SFWS items and scale, Cronbach's alpha coefficients (in parentheses), and intercorrelations of the study variables estimated separately between-subjects (btw) and within-subjects (wth).

\begin{tabular}{|c|c|c|c|c|c|c|c|c|c|c|}
\hline Variables & $M$ & $S D$ & 1. & 2. & 3. & 4. & 5. & 6. & 7. & 8. \\
\hline 1. Btw Item 1 & 2.75 & 0.71 & - & & & & & & & \\
\hline 2. Btw Item 2 & 2.82 & 0.68 & $0.71 *$ & - & & & & & & \\
\hline 3. Btw Item 3 & 2.50 & 0.79 & $0.64 *$ & $0.65^{*}$ & - & & & & & \\
\hline 4. Btw Scale & 2.69 & 0.64 & $0.88 *$ & $0.88^{*}$ & $0.88 *$ & $(0.85)$ & & & & \\
\hline 5. Wth Item 1 & 2.73 & 0.78 & - & - & - & - & - & & & \\
\hline 6. Wth Item 2 & 2.79 & 0.84 & - & - & - & - & $0.57 * *$ & - & & \\
\hline 7. Wth Item 3 & 2.53 & 0.90 & - & - & - & - & $0.55^{* *}$ & $.54 * *$ & - & \\
\hline 8. Wth Scale & 2.68 & 0.70 & - & - & - & - & $0.83 * *$ & $.84^{* *}$ & $.84 * *$ & (0.79) \\
\hline
\end{tabular}

Note. $n=118, n$ observations $=468$. Range of response scale: $1-4$. "-" means that the corresponding statistic cannot be estimated. ${ }^{*} p<.01, * * p<.001$. 


\section{Figure 1}

Study 2: Unstandardized/standardized factor loadings and measurement errors of the SFWS items estimated using confirmatory factor analysis (CFA) assuming scalar invariance.

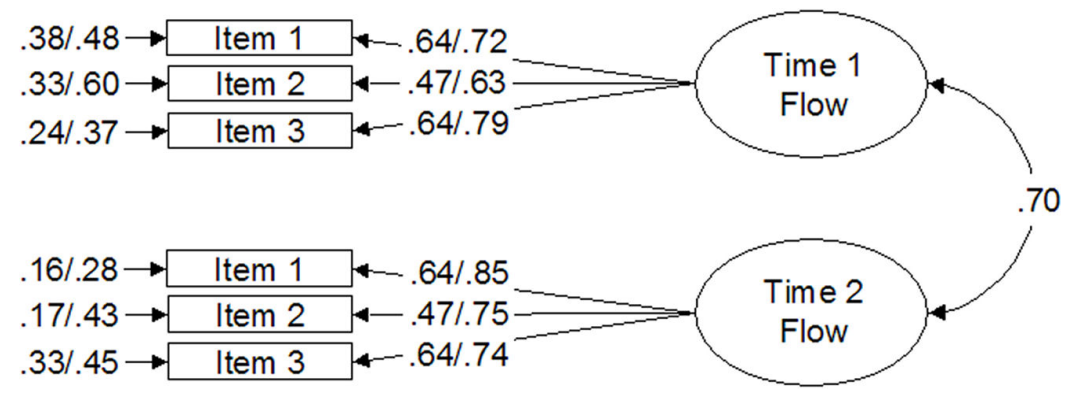

Note. $n=101$. 


\section{Figure 2}

Study 3: Standardized factor loadings of the SFWS, Flow Short Scale (FSS), Short Dispositional

Flow Scale-2 (SDFS-2), Utrecht Work Engagement Scale (UWES-9), I-PANAS-SF Positive

Affect items, and between-factors correlations estimated using confirmatory factor analysis (CFA).

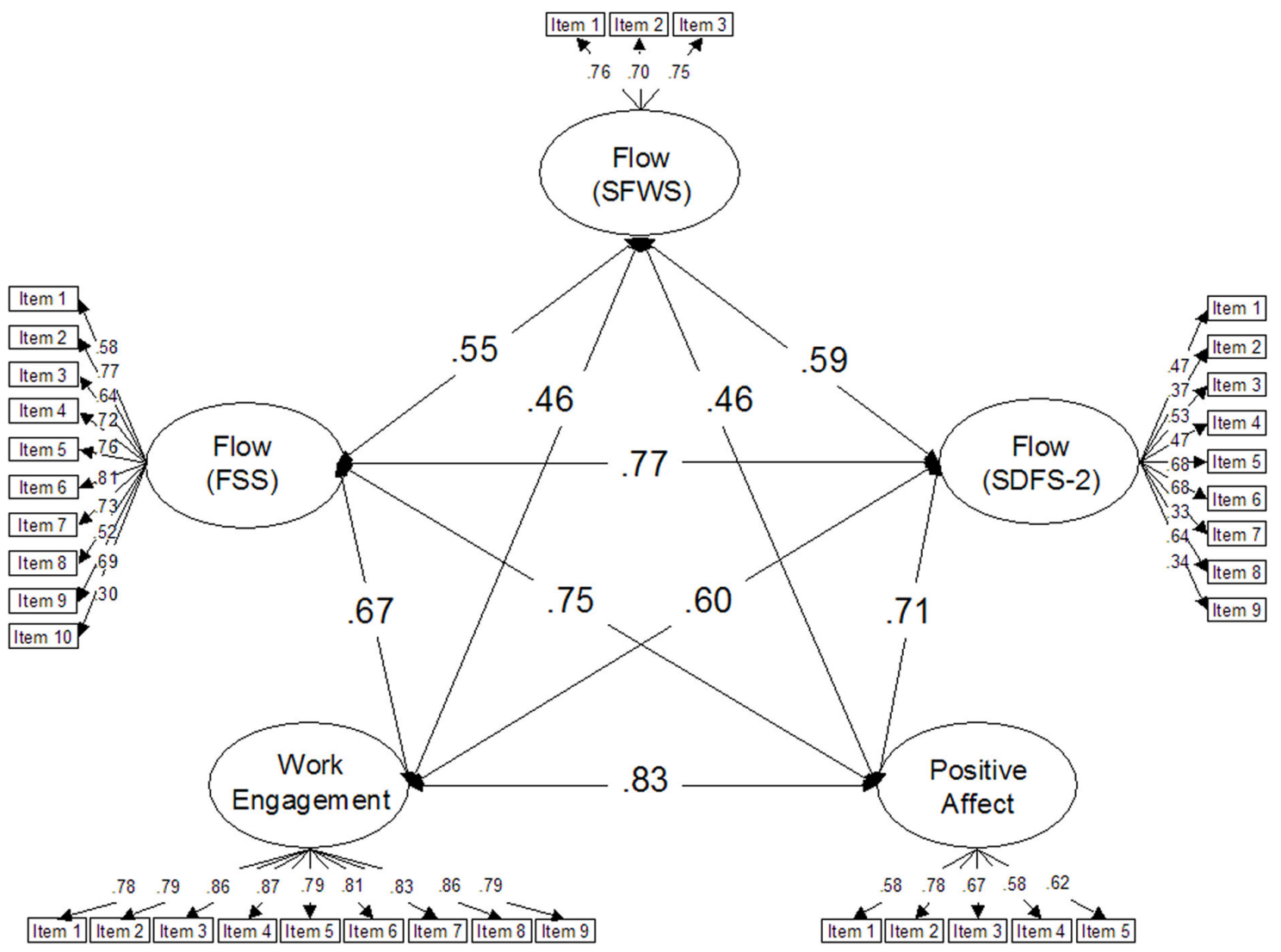

Note. $n=492$. 


\section{Figure 3}

Study 4: Unstandardized/standardized factor loadings and measurement errors of the SFWS items for the between-subjects and within-subjects models estimated using multilevel confirmatory factor analysis (MCFA) assuming invariant factor loadings.

\section{Between-Subjects}

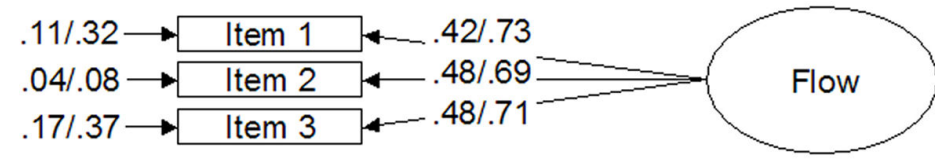

\section{Within-Subjects}

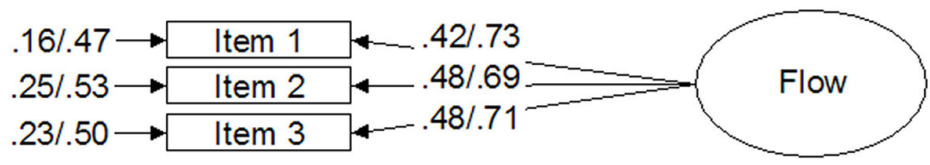

Note. $n=118, n$ observations $=468$. 


\section{Appendix:}

\section{The Short Flow in Work Scale (SFWS)}

\section{Instructions for Participants}

Please rate each item in terms of how true it is of you. Please select one letter for each

question according to the following scale:

$\mathrm{N}$ - Never or almost never true of you

S- Sometimes true of you

O- Often true of you

A- Always or almost always true of you

Items

1. When I get really involved in my work my concentration becomes like my breathing ... I never think of it.

2. Sometimes when I am working I become so absorbed that I am less aware of myself and my problems.

3. When I am working I am so involved in it that I don't see myself as separate from what I am doing. 